\title{
Spawning Biomass Variation in Atlantic Cod (Gadus morhua) in Flemish Cap in Relation to Changes in Growth and Maturation
}

\author{
F. Saborido-Rey \\ Instituto de Investigaciones Marinas, \\ Eduardo Cabello, 6. 36208 Vigo, Spain \\ and \\ S. Junquera \\ Instituto Español de Oceanografía \\ Punta del Apio-San Miguel de Oya, Apdo. 1552, 36280 Vigo
}

\begin{abstract}
Drastic changes in both age- and length-at-maturity of cod (Gadus morhua) on Flemish Cap have been observed during this decade. In the present paper, growth by cohort in this period was analyzed and compared with the observed trend in maturation. Different cohorts displayed different growth rates, the strongest 1990 year-class showing fastest growth. The compensatory response to lower population density alone did not explain the decline in both age- and size-at-maturity. Strong changes in fishing pressure during the period could have provoked a size-selectivity for early maturity, i.e. genetic selection. An estimate of the spawning biomass, accounting for the corresponding size-at-age distributions, on a cohort basis is given. The influence of changes in spawning biomass and spawning stock biomass age structure on the probability of future stock rebuilding is also discussed. It is shown a low spawning biomass composed of young and recruited females will hardly rebuild the stock to historical levels.
\end{abstract}

Key words: biomass, cod, Flemish Cap, growth, maturity

\section{Introduction}

The Flemish Cap is a traditional fishing area for cod (Gadus morhua) in the Northwest Atlantic for the European Union fleet (mainly Spain and Portugal). Cod in this area are managed as a single independent unit stock (Anon., 1997; de Cárdenas, 1995) which is one of the very few stocks still open for fishing in the Northwest Atlantic (Anon., 1997). The Flemish Cap cod stock was itself under a fishing moratorium from 1988 to 1990 and currently all the indices show that its abundance is severely reduced (Vázquez et al., MS 1998; Vázquez and Motos, MS 1998; Anon., 1997).

Despite of the improvement in the scientific advice with the incorporation of new models in terms of uncertainty, the lack of biological realism can produce inappropriate model assumptions, as for example those concerned with static life history parameters (Helser and Brodziak, 1998). Several studies confirm that population density is an important mechanism in regulating the dynamics of marine fish populations (Trippel, 1995; Tyler et al., 1997) affecting several life history parameters, such as growth and age/size and maturity (Roff, 1984) and hence the possibility of the spawning biomass to increase in order to permit the rebuilding of the stock. In Flemish Cap cod a progressive reduction in age and size at maturity from 1992 to 1995 has been observed (Saborido-Rey and Junquera, 1998). This reduction was probably a response to low population abundance and accordingly a certain recovering of the population would be expected. However, there was a lack of incoming recruitment in the latest years, which has made the most recent biomass of the Flemish Cap cod be the lowest value recorded.

In this study, we analyzed changes in age- and size-at-maturity of Flemish Cap cod females for the 
period 1992 to 1997 , examining also the maturity ogives by cohort to ascertain when and why those changes were produced. Growth by cohort was also examined to study the possibility of densitydependent growth.

\section{Material and Methods}

A total of 1123 cod ovaries was collected during the July European Union (EU) survey on the Flemish Cap from 1992 to 1997. Hauls ranged from the shallower parts of the bank $(120 \mathrm{~m})$ to depths of 780 $\mathrm{m}$, according to a random stratified design, with haul duration of 30 min (Vázquez et al., MS 1998). Data on sexual maturity for the period from 1992 to 1995 was used from Saborido-Rey and Junquera (1998), for 1996 from Saborido-Rey (MS 1997) and data for the 1997 survey was prepared for this paper following the methodology already described in Saborido-Rey and Junquera (1998).

A total of 20144 otoliths was collected during the EU surveys from 1988 to 1998 . Age readings were used to calculate mean size-at-age by cohort weighted for size frequency at ages every year and cohort. Mean sizes-at-age were compared using an ANOVA. Size-at-age data fitted well to a regression line, therefore nine regression lines were calculated, one for each cohort from 1986 to 1994. Lines were compared using an ANCOVA.

Data on abundance and biomass were used from VPA analysis by Vázquez and Motos (MS 1998) to be considered more consistent and realistic at age 1 . Spawning stock biomass was calculated with maturity ogives taking into account the effect of the length stratification scheme, i e. the weighted method described by Morgan and Hoenig (1997), where the estimated proportion mature at age is:

$$
\hat{M}_{a}=\frac{\sum_{j=1}^{J} \hat{P}(j) \hat{P}(a \mid j) \hat{P}(m \mid a, j)}{\sum_{j=1}^{J} \hat{P}(j) \hat{P}(a \mid j)}
$$

where:

$$
\begin{aligned}
\hat{P}(j)= & \begin{aligned}
& \text { is the estimated fraction of the } \\
& \text { catch that was length } j, \\
& \hat{P}(a \mid j)= \text { is the proportion of the sampled } \\
& \text { fish in length category } j \text { which } \\
& \text { is age } a
\end{aligned} \\
\hat{P}(m \mid a, j)= & \begin{array}{l}
\text { is the proportion of the sampled } \\
\text { fish at age } a \text { which are mature } \\
\text { in the length category } j, \text { and }
\end{array}
\end{aligned}
$$

$$
J \quad=\text { is the number of length classes. }
$$

All statistical analysis were made using Statistica (StatSoft, Inc., 1995).

\section{Results}

Figure 1 shows the proportion of mature at age from 1992 to 1997 surveys. It can be observed there was a drastic reduction in age at maturity during the period analyzed. Age at maturity was around age 5 in 1992 and drop below age 4 in 1994 remained fixed at that age in subsequent years (Table 1). The ogives display a clear sharp knifeedge in the latest years. Figure 2 shows the same tendency in length at maturity, although it was in the 1995 survey when the main reduction in this parameter occurred. Tables 2 and 3 show the proportion of mature females by age and length, respectively, in 1997. The proportions from 1992 to 1996 are described in Saborido-Rey and Junquera (1998) and Saborido-Rey (MS 1997).

Maturity ogives were calculated also by cohort, to ascertain when the main changes took place and what cohort was involved. Figure 3 shows the proportion of mature females at age 3, 4 and 5 for the 1985-93 cohorts. For the year-classes previous to 1990 , about $25 \%$ of the females were mature at age 4, while for the 1990 cohorts and onwards the proportion at that age ranged between $50 \%$ and $75 \%$. At age 5 a similar shift occurred but starting with the 1989 cohort. Almost $100 \%$ of the females were mature at age 5 in the 1989-92 cohorts, compared with around $75 \%$ of the previous yearclasses.

To investigate the cohort growth in the period studied, first the mean size-at-age were calculated for each cohort where data were available. Results are shown in Fig. 4, displaying also the standard deviations. An ANOVA was performed for each age studied (ages 1 to 8 ) showing a significant differences in the mean size-at-age between cohorts (Fig. 4). At age 1, differences between cohorts were smaller than in other ages, though still significant. In 1990, 1993, 1996 and 1997 cohorts showed a higher mean size and after 1990 the mean size was always above of the late-1980s cohorts. At age 2 a progressive increase in the mean size can be observed from $22 \mathrm{~cm}$ in the 1986 cohort to $33 \mathrm{~cm}$ in 1996 cohort. The main shifts occurred in 1988 and 1990 cohort, where the 1990 cohort was almost $10 \mathrm{~cm}$ larger than 1986 ones. A similar pattern was detected at age 3 where 1990 year-class showed the 


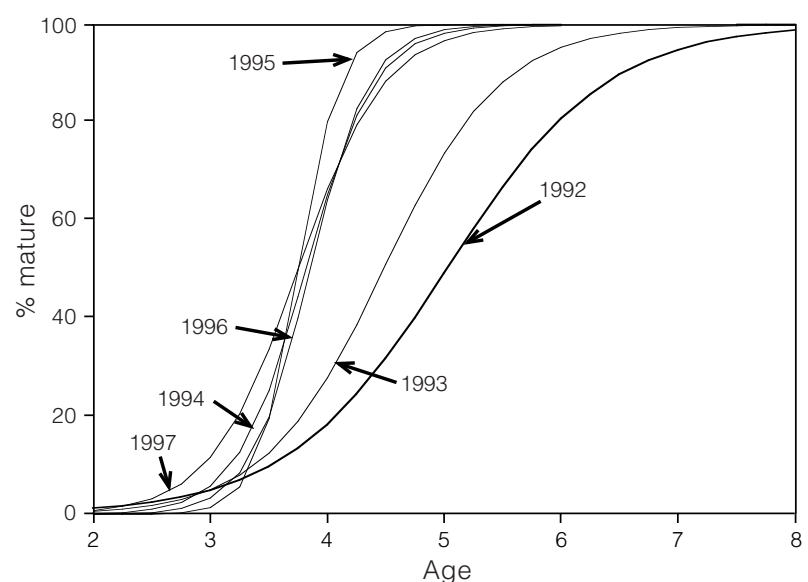

Fig. 1. Proportion of mature females by age (years) from 1992 to 1997.

TABLE 1. Age (years) and length $(\mathrm{cm})$ at maturity of Flemish Cap cod from 1992 to 1997.

\begin{tabular}{ccc}
\hline \hline Year & Age & Length \\
\hline 1992 & 5.02 & 59.38 \\
1993 & 4.48 & 57.53 \\
1994 & 3.82 & 51.23 \\
1995 & 3.75 & 42.65 \\
1996 & 3.85 & 45.86 \\
1997 & 3.75 & 46.14 \\
\hline
\end{tabular}

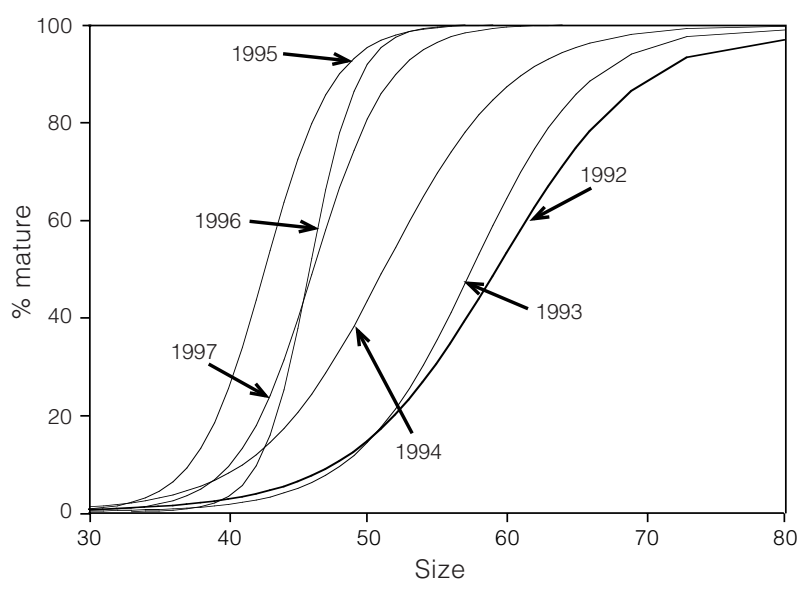

Fig. 2. Proportion of mature females by size (length in cm) from 1992 to 1997.
TABLE 2. Proportion of mature females by age (years) in 1997 (for rest of the years see SaboridoRey and Junquera, 1998 and Saborido-Rey, MS 1997).

\begin{tabular}{ccc}
\hline \hline Age & $\%$ & $\mathrm{n}$ \\
\hline 1 & - & 0 \\
2 & 0 & 10 \\
3 & 5.6 & 71 \\
4 & 73.7 & 95 \\
5 & 90.0 & 10 \\
6 & 96.5 & 57 \\
\hline
\end{tabular}

TABLE 3. Proportion of mature females by length $(\mathrm{cm})$ categories in 1997.

\begin{tabular}{ccc}
\hline \hline Length & $\%$ & $\mathrm{n}$ \\
\hline$<30$ & - & 0 \\
$30-32$ & - & 0 \\
$33-35$ & - & 0 \\
$36-38$ & - & 0 \\
$39-41$ & 8.0 & 2 \\
$42-44$ & 24.0 & 6 \\
$45-47$ & 62.9 & 17 \\
$48-50$ & 72.9 & 27 \\
$51-53$ & 86.2 & 25 \\
$54-56$ & 92.3 & 12 \\
$57-59$ & 92.9 & 13 \\
$>60$ & 100 & 36 \\
\hline
\end{tabular}

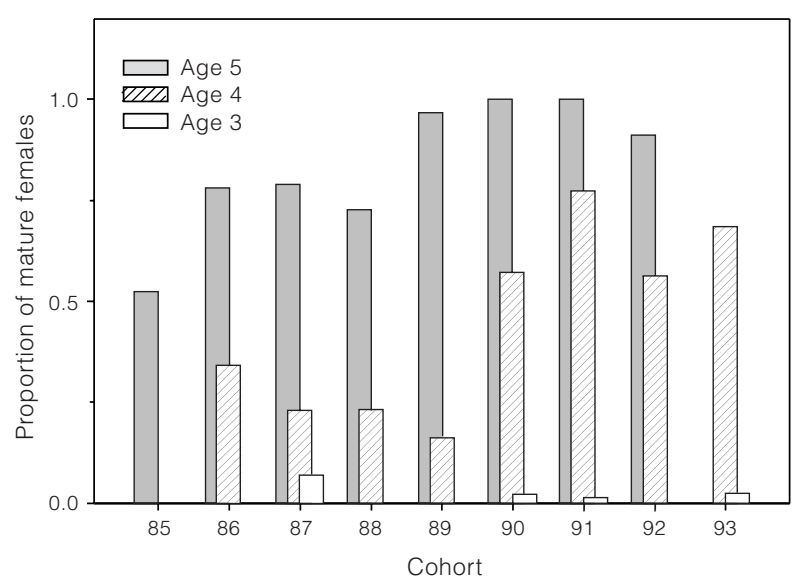

Fig. 3. Proportion of mature females at ages 3 to 5 by cohort from 1985 to 1993. 

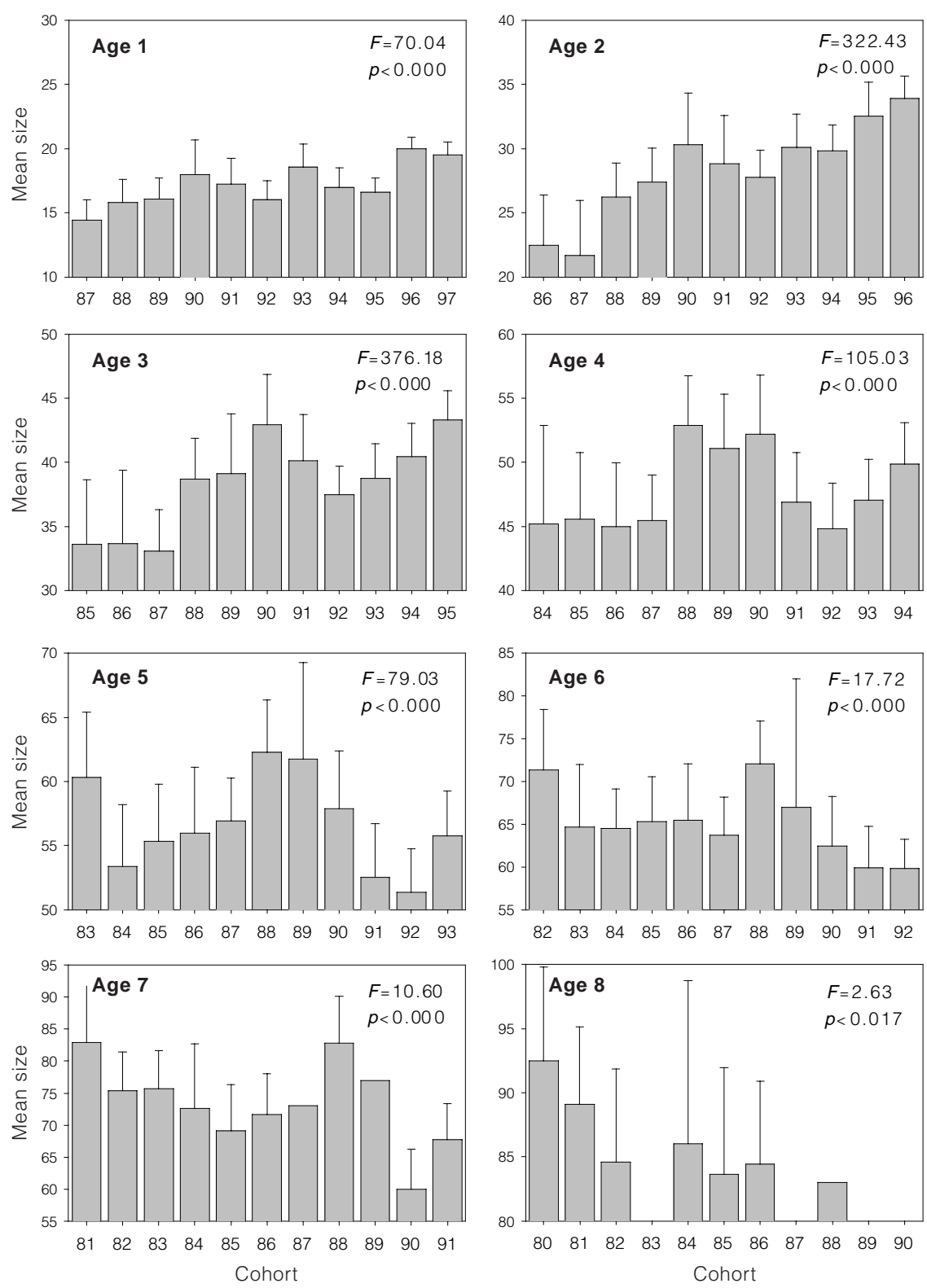

Fig. 4. Mean sizes (length in $\mathrm{cm}$ ) and standard deviations at age by cohort.

highest mean size, $9 \mathrm{~cm}$ above 1986 year-class. The main shift occurred in the 1988 cohort with an increase of $5 \mathrm{~cm}$ in the mean size related with the 1986 year-class. At age 4, the mean size-at-age of 1988, 1989 and 1990 cohorts were similar and significantly higher than previous year-classes. But at this age the mean size of the 1991 and subsequent cohorts showed a considerable lower value than the 1988 to 1990 values and in the same level as the 1984 to 1987 year-classes. The same pattern was observed for age 5. However, for age 6 and 7 it was noticeable that the 1990, 1991 and 1992 cohorts displayed the lower values of mean size for all the cohorts analyzed back to 1981 . At age 8 the data available was scarce and few conclusions can be made. Nevertheless, it is remarkable that there were no fish from the 1989 and 1990 year-classes caught in the surveys. It can be noted also that among the cohorts that were born in the 1990s, the 1992 cohort was the one with lower mean size at all ages. 
Figure 5 shows the regression lines between size and age for each cohort from 1986 to 1993. The coefficient of determination $\left(r^{2}\right)$ was high in all cases, ranging between 0.87 and 0.95 . The lowest values occurred in the regressions of 1986,1990 and 1991 cohorts $(0.87)$ the rest being above 0.92 . Therefore growth curves for cod fitted well to a linear regression probably because fish older than 8 years are seldom caught during the survey (namely 39 fish in eleven surveys). Thus the fish analyzed (age 1 to 7) are in the linear area of the theoretical asymptotic growth curve of Flemish Cap cod. The growth rates for the 1986 and 1987 cohorts were quite similar, $10.5 \mathrm{~cm}$ per year. The 1988 and 1989 cohorts showed an accelerated growth rate (approx. $12 \mathrm{~cm}$ per year). 1990 cohort displayed a similar growth rate to the first two cohorts, i.e. 10.3 $\mathrm{cm}$ per year, but the size at age 1 was the highest, above $20 \mathrm{~cm}$. The 1991 and subsequent cohorts displayed the lowest growth rate (around $9 \mathrm{~cm}$ per year) although the size at age 1 were between the highest also (around $20 \mathrm{~cm}$ ).

These differences in growth pattern between cohorts could be related with the strength of each cohort. To investigate this point the abundance at age (between age 1 and 4) was plotted for 1986 to 1996 year-classes and results are showed in Fig. 6. 1986, 1990 and 1991 were the strongest year-classes at all ages (no data for 1986 cohort at age 1 was available, but it can be assumed using the abundance at age 2 for that cohort). The 1992 and subsequent year-classes were the poorest in all historical series analyzed. It is noticeable that abundance of the 1990 and 1991 cohorts dropped substantially from age 1 to age 4, compared with the mortality at age of other cohorts. Thus, in relation with growth, the strongest year-classes during the 1990s showed a faster growth, which was more conspicuous with the 1990 year-class. Conversely, the 1992 year-class displayed a slower growth rate. It means that there was no densitydependent growth.

Total biomass, spawning biomass and age 5+ spawning biomass are shown in Fig 7. A progressive decrease in total biomass was observed from 1988 to 1997 , with a maximum of 110000 tons in 1989 and a minimum of 13000 tons in 1996. However, changes in spawning stock biomass (SSB) was not so drastic, partially due to the mentioned reduction in age at maturity. In 1996, SSB was in the lowest level with only 6500 tons. Except for 1989 (when the strongest 1986 year-class was age 4) and the SSB was the highest, most of the SSB until 1993 was composed of specimens older than age 4. However, in 1994, 1995 and 1997 most of the SSB was composed of specimens of age 4. As an exception, in 1996, due to the physical growth of the 1990 and 1991 year-classes SSB was older than 4 , but the SSB was the lowest value recorded.

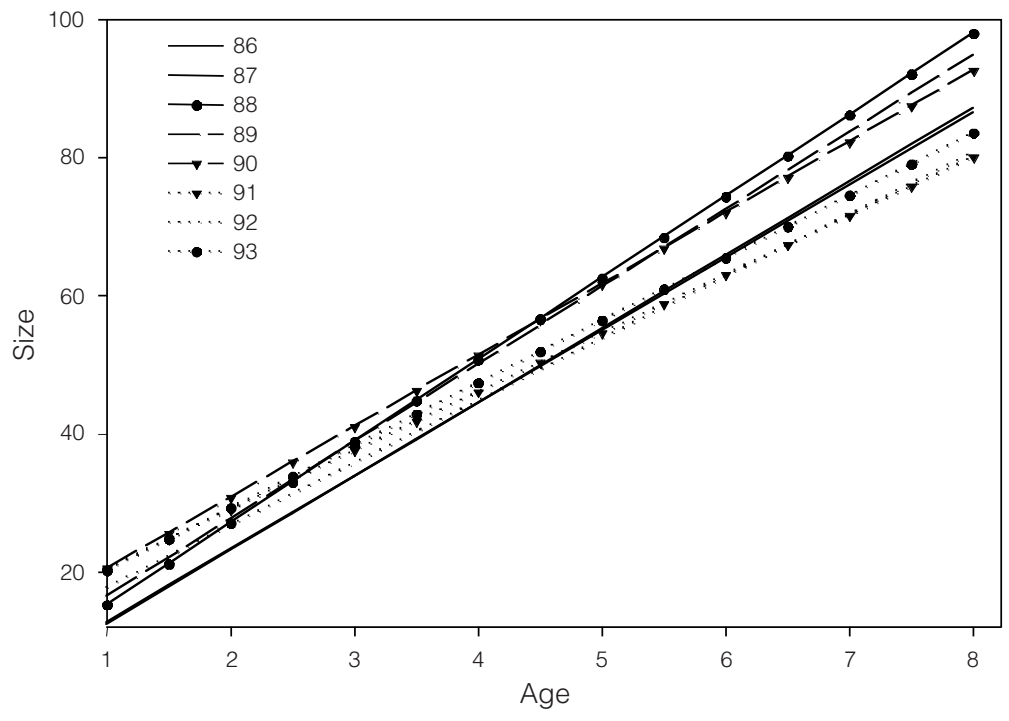

Fig. 5. Regression lines between size (length in $\mathrm{cm}$ ) and age (years) by cohort. $0.86<r^{2}<0.95$. 


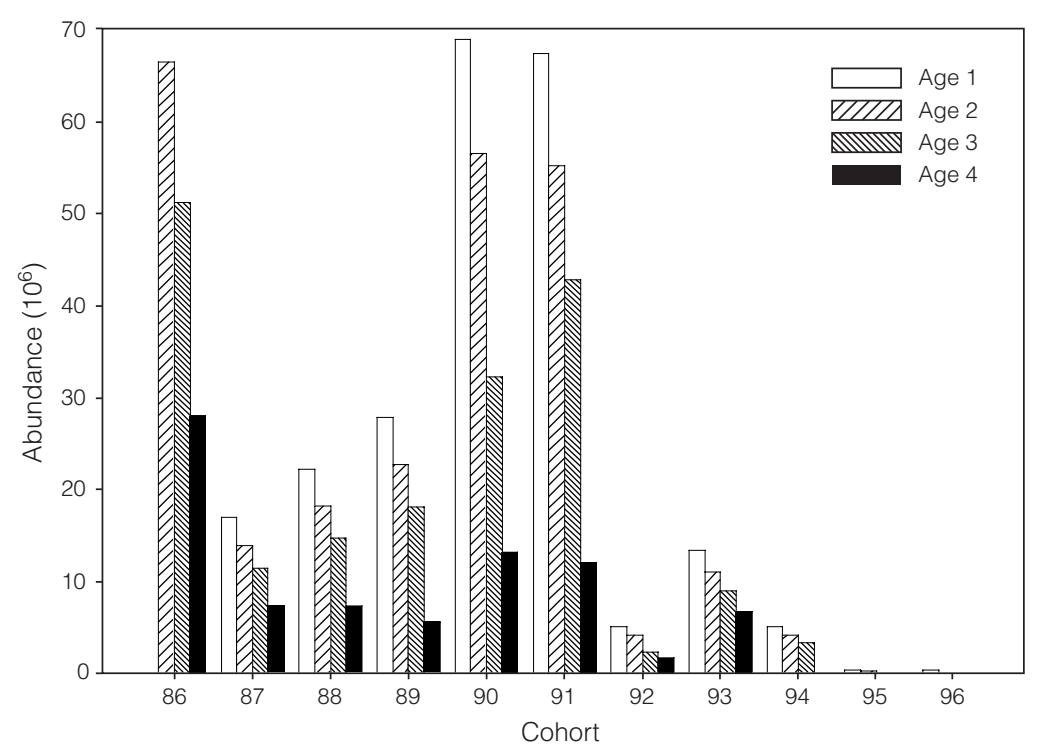

Fig. 6. Abundance at ages 1 to 4 by cohort.

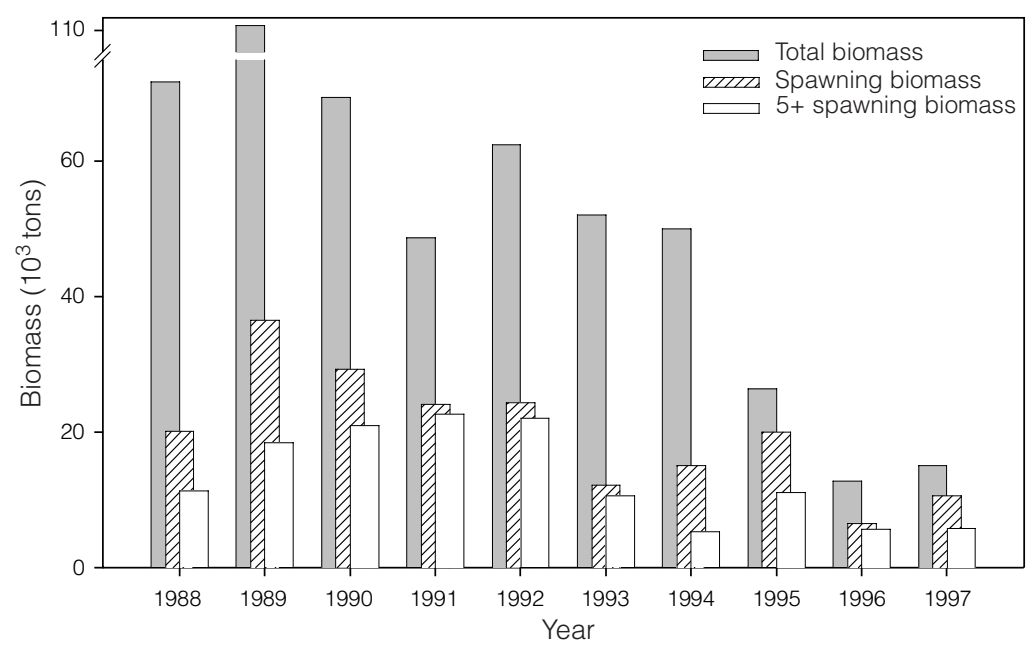

Fig. 7. Total biomass, spawning stock biomass and age 5+ spawning biomass from 1988 to 1997.

Fishing mortality for ages 1 to 7 in the period analyzed are shown in Table 4 . It can be observed that there was a period with high fishing pressure (marked in bold) corresponding to the fishing activity during the years 1992 to 1995 . Especially relative high values were found for the cohorts 1990 and 1992 at age 2 and for the cohorts from 1988 to 1991 at ages 3 and 4 . The extreme high values of fishing mortality of 1985, 1986 and 1987 cohorts at ages 5 to 7 explain the rapid decline of old fish between 1992 and 1994 (Fig. 7), since the mortalities for latter cohorts (1988 to 1991) were high at youngest ages, very few fish reached age older than 5 after 1994.

\section{Discussion}

Size- and age-at-maturity have drastically declined in the period analyzed. According to the results, the main reduction of age-at-maturity would have occurred in the early-1990s, as has also been reported by Morgan and Brattey (MS 1996) in the Newfoundland shelf cod. 
TABLE 4. Fishing mortalities for 1982 to 1995 cohorts at age 1 to 7 of Flemish Cap cod.

\begin{tabular}{|c|c|c|c|c|c|c|c|c|c|c|c|c|c|c|}
\hline \multirow[b]{2}{*}{ Age } & \multicolumn{14}{|c|}{ Cohort } \\
\hline & 1982 & 1983 & 1984 & 1985 & 1986 & 1987 & 1988 & 1989 & 1990 & 1991 & 1992 & 1993 & 1994 & 1995 \\
\hline 1 & & & & & & 0.00 & 0.00 & 0.00 & 0.00 & 0.00 & 0.00 & 0.00 & 0.00 & 0.00 \\
\hline 2 & & & & & 0.06 & 0.00 & 0.02 & 0.03 & 0.36 & 0.06 & 0.40 & 0.00 & 0.02 & 0.00 \\
\hline 3 & & & & 0.41 & 0.41 & 0.24 & 0.50 & 0.98 & 0.69 & 1.07 & 0.14 & 0.09 & 0.32 & \\
\hline 4 & & & 0.52 & 0.83 & 0.98 & 0.36 & 1.36 & 1.23 & 1.19 & 0.93 & 0.25 & 0.14 & & \\
\hline 5 & & 0.48 & 1.23 & 1.33 & 0.52 & 2.33 & 1.14 & 0.39 & 2.66 & 0.36 & 0.17 & & & \\
\hline 6 & 0.69 & 0.71 & 1.26 & 0.75 & 1.06 & 2.85 & 0.72 & 3.53 & 0.73 & 0.15 & & & & \\
\hline 7 & 1.03 & 0.70 & 0.69 & 2.31 & 0.50 & 3.96 & 2.74 & 0.00 & 1.26 & & & & & \\
\hline
\end{tabular}

Size- and age-at-maturity are highly plastic parameters that change under external pressure, particularly with a decrease in the population abundance (Adams, 1980; Gunderson, 1980; Wootton, 1990). Examples of this are plentiful, both in cod (Beacham, 1983; Morgan and Brattey, MS 1996; Jørgensen, 1990) and in many other commercial fish stocks in the North Atlantic. The Flemish Cap cod total biomass declined from 103 644 tons. in 1989 to only 9063 tons. in 1997 (Vázquez et al., MS 1998). In the same way, catch at age showed a parallel decrease, especially in the oldest individuals: $22.5 \%$ of the females were adults in 1990, compared with only $3 \%$ in 1992 and $7 \%$ in 1993 (Saborido-Rey and Junquera, 1998). If the indicated reduction were a response to a decline in the population abundance, then an accelerated growth under a lower stock density would be expected and individuals would mature at younger ages without changing length at maturity (Alm, 1959), although in most of the reported changes on maturity, both age and size decline together (Trippel, 1995). We concluded that the mentioned reduction started with the onset of the 1990 cohort. And indeed, it can be also concluded according to the results, that an accelerated growth occurred during the 1990 cohort and onwards. Nevertheless, the 1990 and 1991 cohort together with the 1986 were the largest in the Flemish Cap historical series analyzed here. Contrary to the background assumptions of the density-dependence hypothesis, both 1990 and 1991 achieved a faster growth though being very abundant, while 1986 did not. This explains why cod got mature at younger ages. But it failed to explain why a reduction in size at maturity also occurred. One possible reason is that both 1990 and 1991 cohorts, contrary to the situation existing in 1986, were the only abundant cohorts within a quite long period of time, thus population density at that moment should be greatly reduced related to previous years.

Fishing pressure during the period changed a lot, affecting each cohort and each age in different manners. It is difficult to assess here how this selective fishing mortalities has influenced each cohort and hence their life history parameters. Trippel (1995) has pointed out genetic selection as an important factor to explain the decline in ageand size-at-maturity. In heavily exploited populations, fish maturing late have fewer chances to reproduce than those maturing earlier. During 1992 to 1995 the fishing mortalities were the highest over the period for older ages, and accordingly we can assume that at each age smaller fish have a likely higher probability to survive. Cohorts 1989-91 faced a totally different fishing pressure during age 2-4 than the previous cohorts. In general, the different behavior of the cohorts in response to changes in population density probably is a consequence of a mix of factors having both compensatory and genetic origins.

If the reduction of age/size at maturity should be seen as a response to low fish densities, which could generate an increase of the spawning stock, the stock on the contrary showed a systematic failure to recover. Since 1992 the spawning stock included only two year-classes, that besides are composed of early maturing females (Saborido-Rey and Junquera, 1998). In addition these cohorts were virtually fished out before reaching age 5, giving a completely age truncated SSB. The reproductive potential of one age-truncated stock whose spawning biomass is based on young females is not equivalent to the same spawning biomass of large females as it is known that older females have a longer spawning season, higher fecundity and 
produce larger eggs and hence larger larvae than do the younger ones (Buzeta and Waiwood, 1982; Kjesbu et al., 1991; Kjesbu, 1989; Solemdal et al., MS 1992). Thus, it seems clear that offspring of older cod are more likely to survive. The trend shown by the Flemish Cap cod stock in latter years therefore demonstrates that the current demographic structure is likely to be unable to recover the stock to sustainable levels.

\section{Acknowledgements}

This study was supported by the European Commission (DG XIV, Study 96-030), Instituto Español de Oceanografía, and Consejo Superior de Investigaciones Científicas.

\section{References}

ADAMS, P. B. 1980. Life history patterns in marine fishes and their consequences for fisheries management. Fish. Bull., 78: 1-12.

ALM, G. 1959. Connection between maturity, size and age in fishes. Inst. Freshwater Res. Drottningholm Rep., 40: 5-145.

ANON. 1997. Scientific Council Reports, 1996. NAFO Sci. Coun. Rep., 1996, p. 5-138.

BEACHAM, T. D. 1983. Variability in median size and age at sexual maturity of Atlantic cod (Gadus morhua) on the Scotian shelf in the Northwest Atlantic Ocean. Fish. Bull., 181(2): 303-321.

BUZETA, M. I., and K. G. WAIWOOD. 1982. Fecundity of Atlantic cod (Gadus morhua) in the southwestern Gulf of St. Lawrence. Can. Tech. Rep. Fish. Aquat. Sci., 1110.

DE CÁRDENAS, E. 1995. Dinámica de la población de bacalao de Flemish Cap; consideraciones sobre su aislamiento y gestión. Ph.D. Thesis, Univ. Complutense, Madrid. 237 p.

GUNDERSON, D. R. 1980. Using $r$ - $K$ selection theory to predict natural mortality. Can. J. Fish. Aquat. Sci., 37: 2266-2271.

HELSER, T. E. and J. K. T. BRODZIAK. 1998. Impacts of density-dependence growth and maturation on assessment advice to rebuild depleted U. S. silver hake (Merluccius bilininearis) stocks. Can. J. Fish. Aquat. Sci., 55: 882-892.

JØRGENSEN, T. 1990. Long-term changes in age at sexual maturity of Northeast Arctic cod (Gadus morhua L.). ICES J. Cons., 46: 235-248.

KJESBU, O. S. 1989. The spawning activity of cod, Gadus morhua L. J. Fish. Biol., 34: 195-206.

KJESBU, O. S., J. KLUNGSØYR, H. KRYVI, P. R. WITTHAMES, and M. GREER WALKER. 1991. Fecundity, atresia, and egg size of captive Atlantic cod (Gadus morhua) in relation to proximate body composition. Can. J. Fish. Aquat. Sci., 48: 23332343.

MORGAN, M. J., and J. BRATTEY. MS 1996. Maturity of female cod in 2J3KL. DFO Atl. Fish., Res. Doc., No. 64.

MORGAN, J. and J. M. HOENIG. 1997. Estimating maturity-at-age from length stratified sampling. J. Northw. Atl. Fish. Sci., 21: 51-64.

ROFF, D. A. 1984. The evolution of life history parameters in teleosts. Can. J. Fish. Aquat. Sci., 41: 989-1000.

SABORIDO-REY, F. and S. JUNQUERA. 1998. Histological assessment of variations in sexual maturity of cod (Gadus morhua L.) at the Flemish Cap (North-west Atlantic). ICES J. Mar. Sci., 55: 515-521.

SABORIDO-REY, F. MS 1997. Sexual maturity and spawning biomass of the Flemish Cap cod (Div. 3M). NAFO SCR Doc., No. 18, Serial No. N2848, 9 p.

SOLEMDAL, P., O. BERGH, R. N. FINN, H. J. FYHN, O. GRAHL-NIELSEN, O. HOMME, O. S. KJESBU, E. KJØRSVIK, I. OPSTAD and A. B. SKIFTESVIK. MS 1992. The effect of maternal status of ArctoNorwegian cod on egg quality and vitality of early larvae. II. Preliminary results of the experiment in 1992. ICES C.M. Doc., No. G:79.

STATSOFT, INC. 1995. STATISTICA for Windows [Computer program manual]. Tulsa, OK.

TRIPPEL, E. A. 1995. Age at maturity as a stress indicator in fisheries. BioScience, 45(11): 759-771.

TYLER, J. A., K. A. ROSE and R. C. CHAMBERS. 1997. Compensatory responses to decreased young-of-the year survival: an individual-based modelling analysis of winter flounder. In: Early life history and recruitment in fish populations. Chambers and Trippel (Eds.) Chapman and Hall, London. p 391-422.

VÁZQUEZ, A. and L. MOTOS. MS 1998. An assessment of the cod stock in NAFO Division 3M. NAFO SCR Doc., No. 52, Serial No. N3043, 15 p.

VÁZQUEZ, A., A. ÁVILA DE MELO and F. SABORIDOREY. MS 1998. Results from bottom trawl survey of Flemish Cap in July 1997. NAFO SCR Doc., No. 30, Serial No. N3017, 38 p.

WOOTTON, R. J. 1990. Ecology of teleost fishes. Chapman and Hall, London, 404 p. 